\title{
Gallstones top to toe: what the radiologist needs to know
}

\author{
M. C. Murphy", B. Gibney, C. Gillespie, J. Hynes and F. Bolster
}

\begin{abstract}
Gallstone-related disease can have significant associated morbidity and mortality worldwide. The incidence of gallstone-related disease in the Western world is on the increase. There are multiple different pathological manifestations of gallstone disease: the presentation, diagnosis and associated complications of which vary significantly depending on anatomical location. The role of imaging in gallstone-related disease is broad with radiology playing an essential role in the diagnosis, management and follow-up of gallstonerelated pathologies. This paper distills the broad range of gallstone-related pathologies into an anatomical map, discussing the disease processes involved at each point along the biliary tree and reviewing the strengths and weaknesses of different imaging modalities for each distinct disease process.
\end{abstract}

Keywords: Gallstones, Gallbladder, Biliary, Calculus, Pathology

\section{Key points}

- Gallstone-related pathology is on the increase in the Western world.

- Gallstones can be located within the gallbladder, migrate into the biliary tree or outside the pancreaticobiliary system altogether with associated pathology.

- Imaging of gallstones and associated pathology requires a multimodality approach.

\section{Introduction}

Gallstones are solid rounded particles composed of a combination of cholesterol and bilirubin that form within the gallbladder and within the biliary system. The size and number of gallstones is variable with some patients forming multiple small gallstones and others forming single or few large stones.

The incidence of gallstones is increasing in Western populations as obesity levels rise. In the USA, $8.6 \%$ of Caucasian men and $16.6 \%$ of women have gallstones [1]. The vast majority of gallstones

\footnotetext{
* Correspondence: mark.murphy@ucdconnect.ie

Department of Radiology, Mater Misericordiae University Hospital, Eccles St, Dublin 7, Ireland
}

are asymptomatic and require no follow-up; however, approximately $10-15 \%$ of gallstones will become symptomatic over a period of 10-15 years of followup $[2,3]$. The symptomatic manifestations of gallstones are variable and range from mild symptoms such as biliary colic to severe acute presentations such as pancreatitis, which can be associated with significant morbidity and mortality. In a patient that has suffered a symptomatic manifestation of gallstones, the incidence of a further manifestation over their lifetime is approximately $3 \%$ per year [2]. The risk for gallstone-related pathology is also related to the number and size of stones with numerous larger stones more likely to cause symptoms. For this reason, it is suggested that once symptoms present, the patient should be offered a cholecystectomy [3-5].

The main risk factors for gallstone formation are outlined in Table 1, and the factors protective against gallstones are outlined in Table 2.

There are three main types of gallstones: cholesterol, mixed and pigmented. Cholesterol gallstones account for $10 \%$ of gallstones and are composed of at least $50 \%$ cholesterol and form with supersaturation of bile. Patients with high-fat diets and high serum lipids are more likely to have a higher cholesterol composition. Pigmented gallstones, which are darker in colour and are composed mainly of 
Table 1 Main risk factors for gallstone formation

\begin{tabular}{ll}
\hline Risk factors for gallstone & Comment \\
formation & $\begin{array}{l}\text { The incidence increases with age but } \\
\text { symptomatic presentation is most } \\
\text { common in middle age. } \\
\text { More common in females by a ratio } \\
\text { of 2:1. } \\
\text { Gender }\end{array}$ \\
Race & $\begin{array}{l}\text { Hispanic and Native American } \\
\text { populations. }\end{array}$ \\
Family history & $\begin{array}{l}\text { A first degree relative with a history } \\
\text { of gallstones doubles the risk. }\end{array}$ \\
Obesity & $\begin{array}{l}\text { Increased risk of cholesterol stone } \\
\text { formation. }\end{array}$ \\
Rapid weight loss & $\begin{array}{l}\text { Bile stasis due to reduced calorie intake } \\
\text { and increased cholesterol mobilisation. }\end{array}$ \\
Haemolysis & $\begin{array}{l}\text { There is an increased incidence of } \\
\text { associated with haemolytic disorders } \\
\text { such as sickle cell disease and the } \\
\text { thalassemias. }\end{array}$ \\
Cirrohosis &
\end{tabular}

bilirubin with $<20 \%$ cholesterol, form with supersaturation of unconjugated bilirubin. There are two subtypes of pigmented gallstones: black pigmented gallstones which are formed due to chronic haemolysis, cirrhosis or intestinal malabsorption, and brown pigmented gallstones which are formed secondary to bacterial and parasitic infections such as Clonorchis sinensis or due to stasis of bile. Finally, mixed gallstones account for $80 \%$ of gallstones and have a cholesterol content of $20-50 \%[6,7]$.

\section{Imaging in gallstone-related disease}

Multiple imaging modalities play a role in the diagnosis of the broad spectrum of gallstone-related disease including plain radiography, ultrasonography, computed tomography (CT), scintigraphy and magnetic resonance imaging (MRI).
Table 2 Factors protective against gallstones

\begin{tabular}{ll}
\hline $\begin{array}{l}\text { Factors protective against gallstone } \\
\text { formation }\end{array}$ & Comment \\
\hline Statins & $\begin{array}{l}\text { Reduce bile cholesterol } \\
\text { concentration }\end{array}$ \\
Ascorbic acid & Alters cholesterol catabolism \\
Unsaturated fats & Alters bile acid composition \\
Coffee & Alters cholesterol catabolism \\
Vegetable proteins and nuts & Increase ascorbic acid levels \\
\hline
\end{tabular}

Ultrasound is by far the most common and useful imaging modality in assessing gallstones within the gallbladder (cholelithiasis) and associated gallbladder pathology and has the added benefit of no radiation dose to the patient. With ultrasound, gallstones are characteristically echogenic and demonstrate posterior acoustic shadowing regardless of the gallstone composition (Fig. 1). As ultrasound is a bedside dynamic study, stone mobility can be demonstrated with patient manoeuvering, and this can help in differentiating gallstones from gallbladder polyps, which can mimic cholelithiasis sonographically.

Another principle advantage of ultrasound over other imaging techniques in the investigation of acute cholecystitis is the ability to evaluate for a sonographic Murphy's sign, which can be a reliable indicator of acute cholecystitis with a high sensitivity [8]. Sonographic Murphy's sign is where the patient reports maximal pain as the sonographer presses over the fundus of the distended gallbladder with the ultrasound probe (and differs to clinical Murphy's sign).

The major limitation of ultrasound in the imaging of gallstone-related disease is the frequent inability to assess the distal common bile duct (CBD) due to overlying bowel gas. Occasionally, a stone can be seen within the biliary system; however, often the presence of a CBD stone can be inferred from visualised proximal biliary dilatation and clinical presentation with painful jaundice or an obstructive pattern on liver function tests. This requires further work up with alternative imaging.

Plain radiography is limited in the diagnosis of gallstones as only $15-20 \%$ of gallstones are radio-opaque on X-ray [6]. The classical radiographic appearance is the "Mercedes Benz sign" which is an outer radioopaque rim with a radiolucent centre which is caused by calcification of the gallstone rim and gas fissuring within the gallstone. Calcification of gallstones occurs with increased calcium in bile [9] (Fig. 2).

On CT, a high percentage of cholesterol stones are hypoattenuating relative to bile (Fig. 3) and calcified 


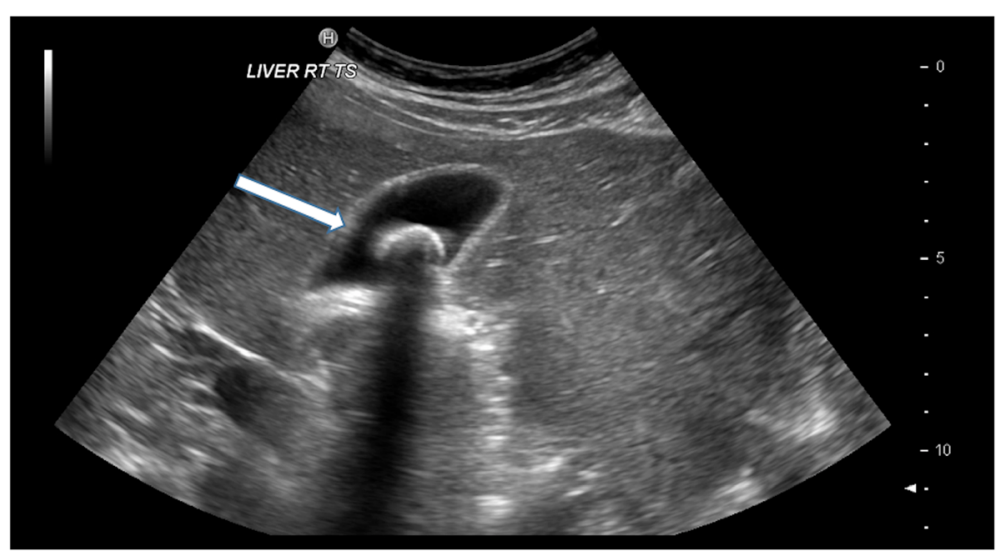

Fig. 1 Sagittal ultrasound image of the gallbladder which demonstrates the typical appearance of a gallstone that is hyperechoic with posterior acoustic shadowing (arrow)

stones are hyperattenuating relative to bile (Fig. 4); however, a significant proportion of stones are isoattenuating relative to surrounding bile and may be radiologically occult on CT. Dual-energy CT has been shown to improve detection of gallstones with low KV imaging and base substance imaging, such as calcium-based and lipid-based imaging, which is more sensitive at detecting gallstones than traditional higher KV imaging. Despite these imaging advances, CT remains inferior to ultrasound at assessing the

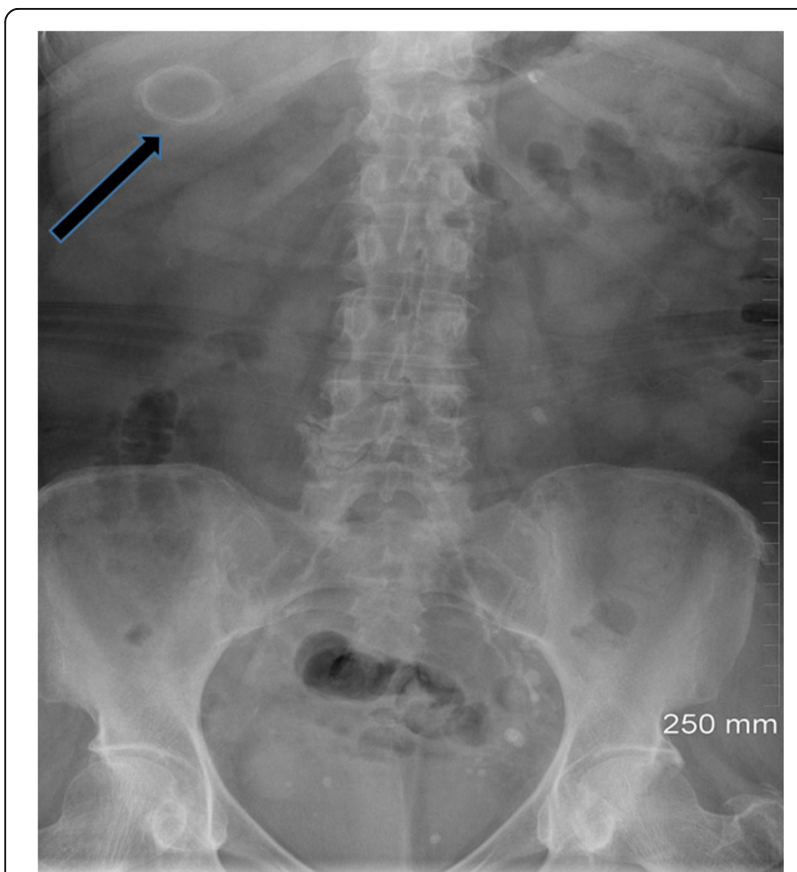

Fig. 2 Abdominal radiograph revealing a large rounded calcified density with a central lucency in the right upper quadrant consistent with a peripherally calcified gallstone gallbladder and results in a significant radiation dose to the patient. As such, ultrasound is the imaging modality of choice for initial assessment of suspected gallbladder pathology. CT however can be very effective at assessing extra-biliary gallstone pathology and complications arising from gallstone pancreatitis and cholecystitis $[8,10]$.

MRI is another very effective tool for diagnosing gallstones and associated pathological processes. Magnetic resonance cholangiopancreatography (MRCP) is typically performed using heavily $\mathrm{T} 2$-weighted sequences, supplemented by fat-saturated $\mathrm{T} 1$ - and $\mathrm{T} 2$ weighted MRI, and with steady-state gradient-echo acquisitions. Heavily T2-weighted image sequences are particularly helpful in delineating ductal anatomy.

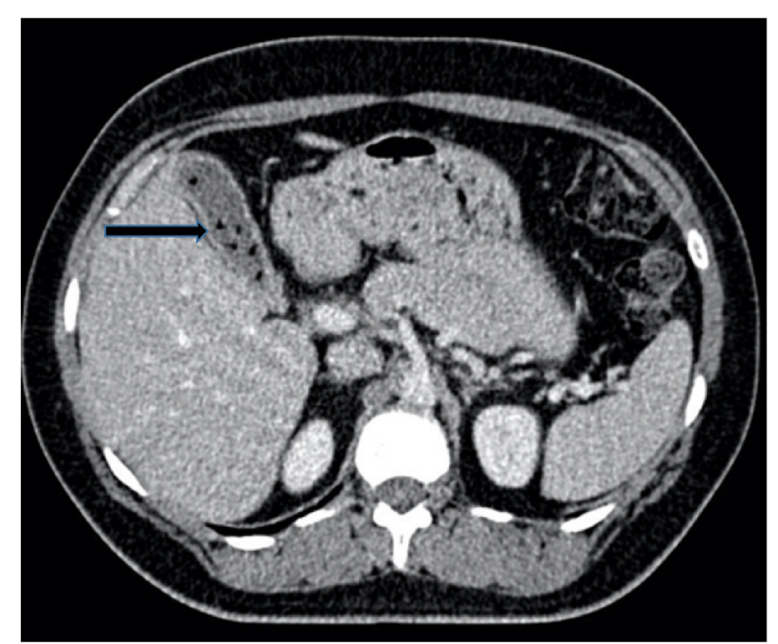

Fig. 3 Axial contrast-enhanced $C T$ of the abdomen. There are multiple small gallstones within the gallbladder which are hypoattenuating relative to the surrounding bile 


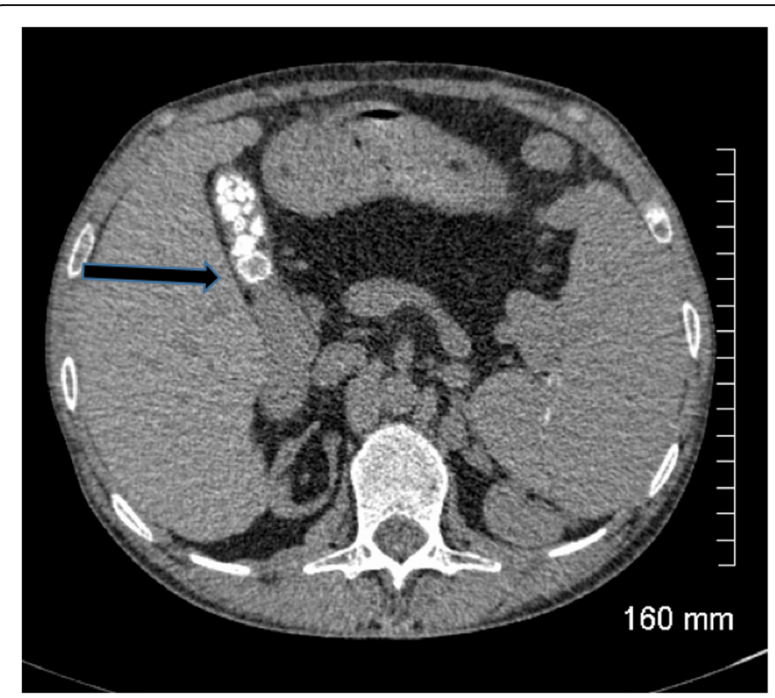

Fig. 4 Axial contrast-enhanced $C T$ of the abdomen. There are several calcified gallstones (arrow) within the gallbladder which are hyper attenuating relative to surrounding bile

Gallstones typically appear as low signal or signal void on T2-weighted imaging surrounded by T2 hyperintense bile [11] (Fig. 5). MRCP has largely replaced endoscopic retrograde cholangiopancreatography (ERCP) as the gold standard for diagnosing choledocholithiasis due to its high sensitivity of 90$94 \%$ and specificity of $95-99 \%$ without the use of ionising radiation or ERCP-related complications such as pancreatitis which can result in significant morbidity and even mortality $[12,13]$.

Nuclear medicine imaging with scintigraphy and with SPECT/CT can be used to dynamically assess

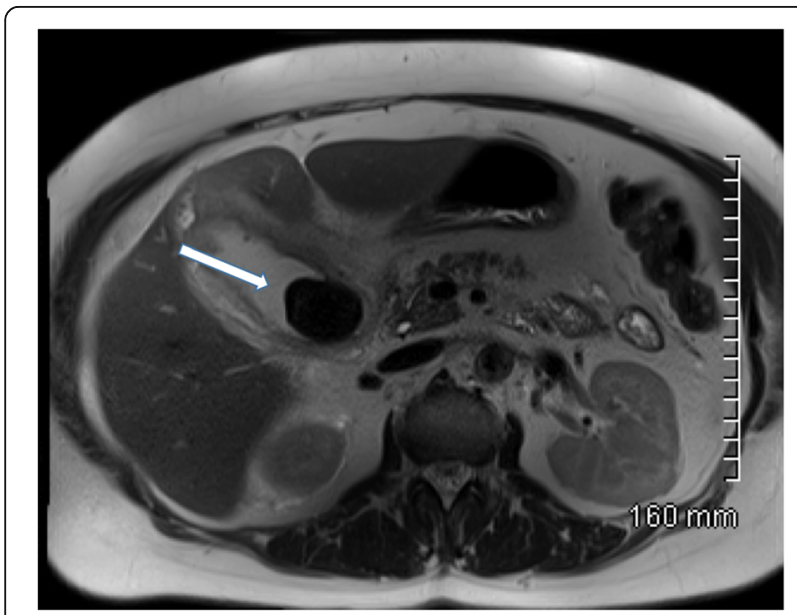

Fig. 5 Axial T2-weighted MRI of the abdomen. There is a large gallstone within the gallbladder which is markedly hypointense relative to the surrounding hyperintense bile. The gallbladder wall is thickened with surrounding pericholecystic fluid consistent with acute cholecystitis

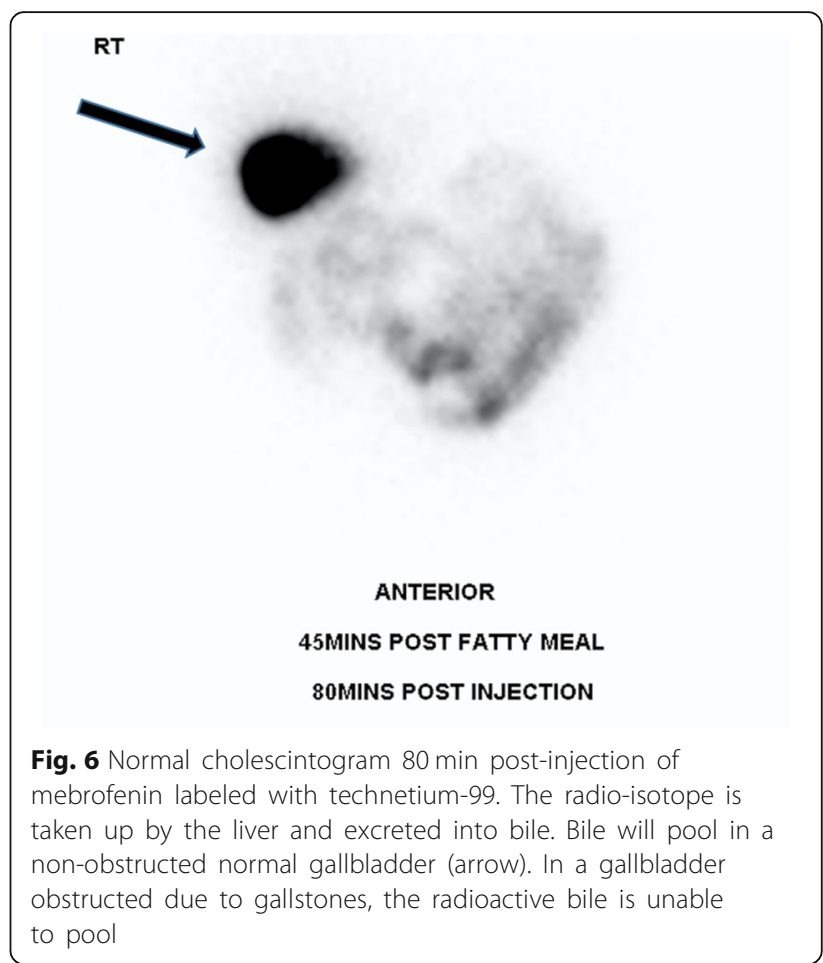

the gallbladder. Technicium-99 labeled mebrofenin is administered and taken up by bile producing cells and subsequently excreted into the biliary system. The patient is typically imaged at $1 \mathrm{~h}$ and at $4 \mathrm{~h}$ post-administration of radioisotope. A normal

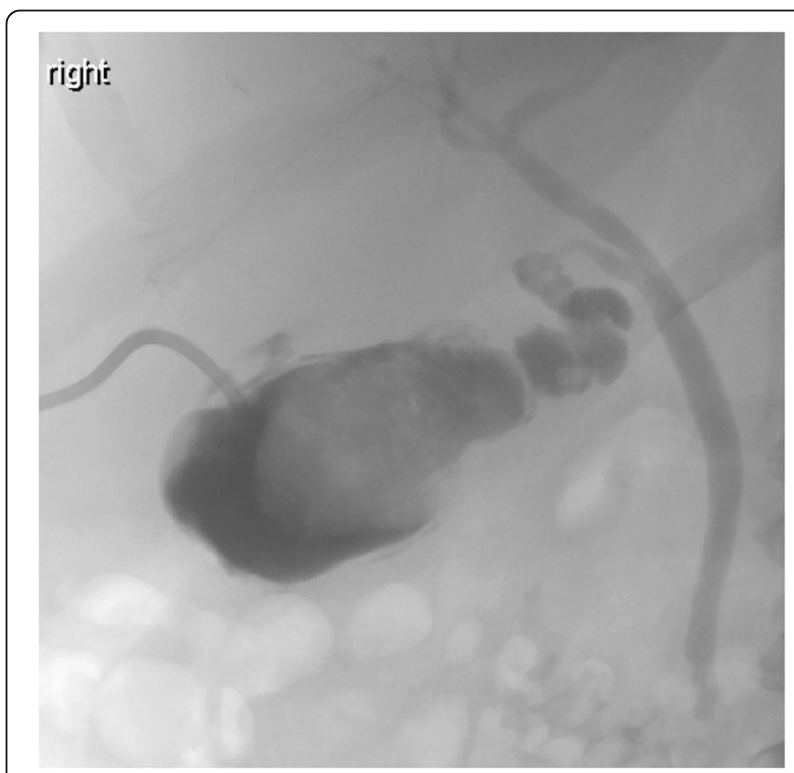

Fig. 7 Cholangiogram via a cholecystostomy tube demonstrating a distended gallbladder with a large filling defect consistent with a gallstone. The cystic duct and common bile duct are patent. Contrast is seen in the duodenum 


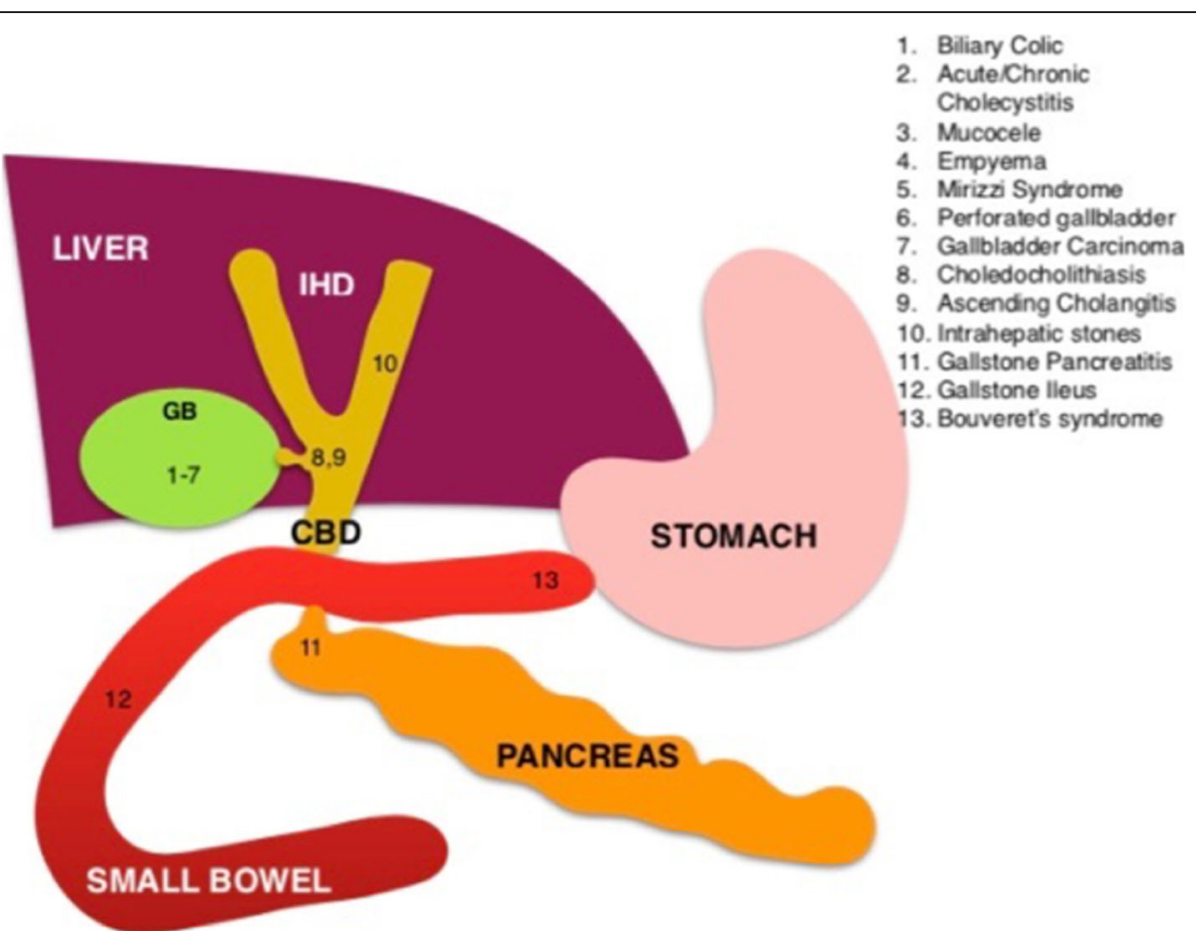

Fig. 8 Illustration outlines the multitude of locations within the digestive tract where gallstones can manifest and lists the pathological processes that occur in these locations

gallbladder will be well delineated as it fills with radioactive bile. In cases of cholecystitis or gallbladder obstruction due to an impacted stone in the cystic duct, the gallbladder will not be visualised as the radioactive will not accumulate within the gallbladder. If the gallbladder is not visualised, morphine analogues can be given to induce sphincter of Oddi

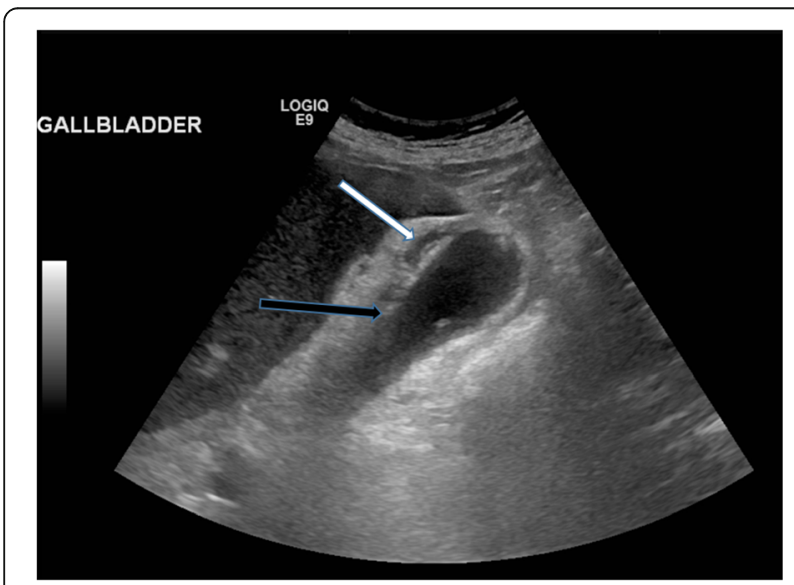

Fig. 9 Sagittal ultrasound image of the gallbladder which contains hyperechoic gallstones. There is gallbladder wall thickening (black arrow) and pericholecystic fluid (white arrow) consistent with acute calculous cholecystitis contraction and aid gallbladder filling. Cholescintigraphy for acute cholecystitis has a sensitivity of $97 \%$ and a specificity of $94 \%$ [14]. This is actually superior to ultrasound; however, this technique is more expensive and time consuming and also confers a radiation dose to the patient and staff and thus is generally not a first-line investigation (Fig. 6).

There is an increasing role for interventional radiology (IR) in gallstone-related diseases. Percutaneous cholecystostomy can be used as a temporizing measure in critically ill patients who are too sick to proceed to immediate surgery and cholecystectomy. It is also occasionally being used as a therapeutic measure in the setting of an ageing population with multiple co-morbidities, many of whom may have contraindications to general anaesthesia and surgical intervention. In patients who have had a cholecystostomy placed, cholangiograms can be performed to demonstrate resolution of or ongoing obstruction of the biliary tree by assessing for filling defects (gallstones) within the biliary system (Fig. 7). Percutaneous transhepatic cholangiography (PTC) with biliary stenting is a very effective treatment to decompress the biliary system in the case of obstructing choledocholithiasis, most often in cases not amenable to ERCP. IR also play an active role in the 


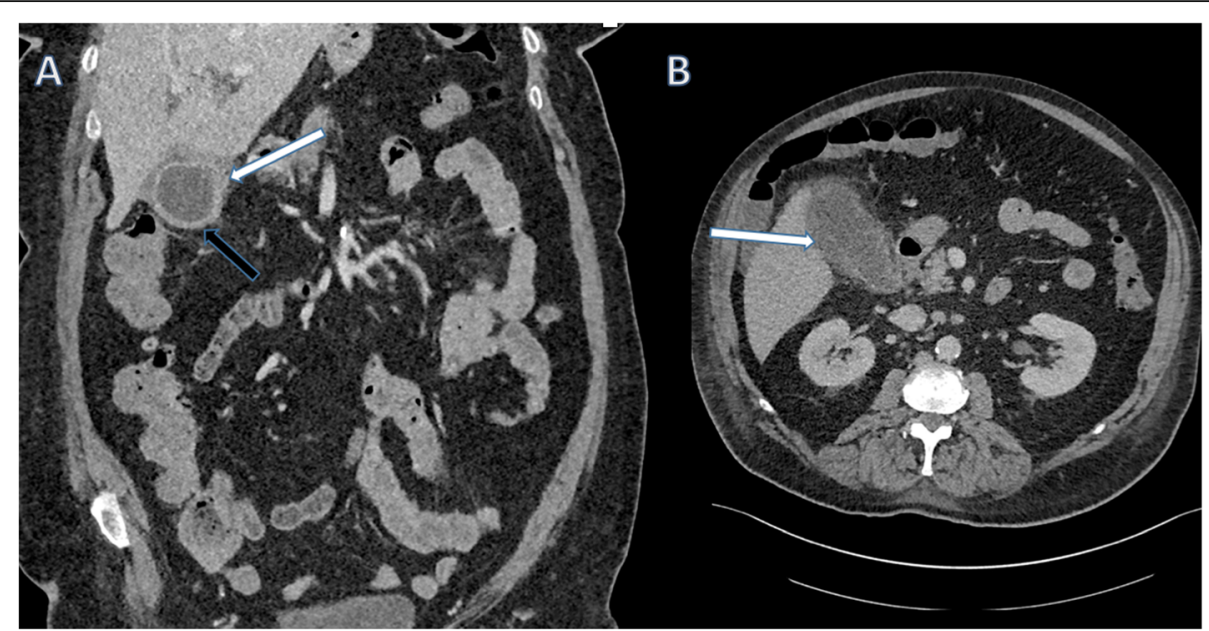

Fig. 10 Coronal (a) and axial (b) contrast-enhanced CT of the abdomen. There is gallbladder wall thickening (black arrow) and pericholecystic fluid (white arrows) consistent with acute cholecystitis

management of the complications of gallstone disease through drain insertion for hepatic or peripancreatic abscesses, in the case of pancreatitis, and for post-operative intra-abdominal collections postcholecystectomy.

\section{Gallstone pathology}

The broad spectrum of gallstone-related disease can be broken down based on the anatomical locations in which they occur (Fig. 8).

\section{Gallbladder}

Unsurprisingly, the most common location for gallstones and thus gallstone-related disease is the gallbladder.

Biliary colic is caused when a stone temporarily obstructs the drainage from the cystic duct, resulting in severe cramping abdominal and right upper quadrant pain that can radiate to the back and right shoulder tip as the gallbladder contracts (typically, these symptoms are temporary and subside with resolution of the cystic duct obstruction). Ultrasonography will often demonstrate cholelithiasis without associated complications in patients with simple biliary colic.

Calculous cholecystitis refers to infection and inflammation of the gallbladder wall caused by irritation from gallstones, and this can be an acute or chronic process. The typical clinical presentation of acute cholecystitis is of right upper quadrant pain, with or without radiation to the right shoulder, which is more constant compared to the intermittent pain seen in biliary colic. There is usually associated pyrexia and other infective symptoms such as nausea and vomiting. The typical imaging features of acute cholecystitis are as follows: gallbladder wall thickening, pericholecystic fluid and a distended gallbladder [8] (Figs. 9 and 10). Chronic cholecystitis is caused by repeated episodes of biliary colic and acute cholecystitis over time, and in contrast to

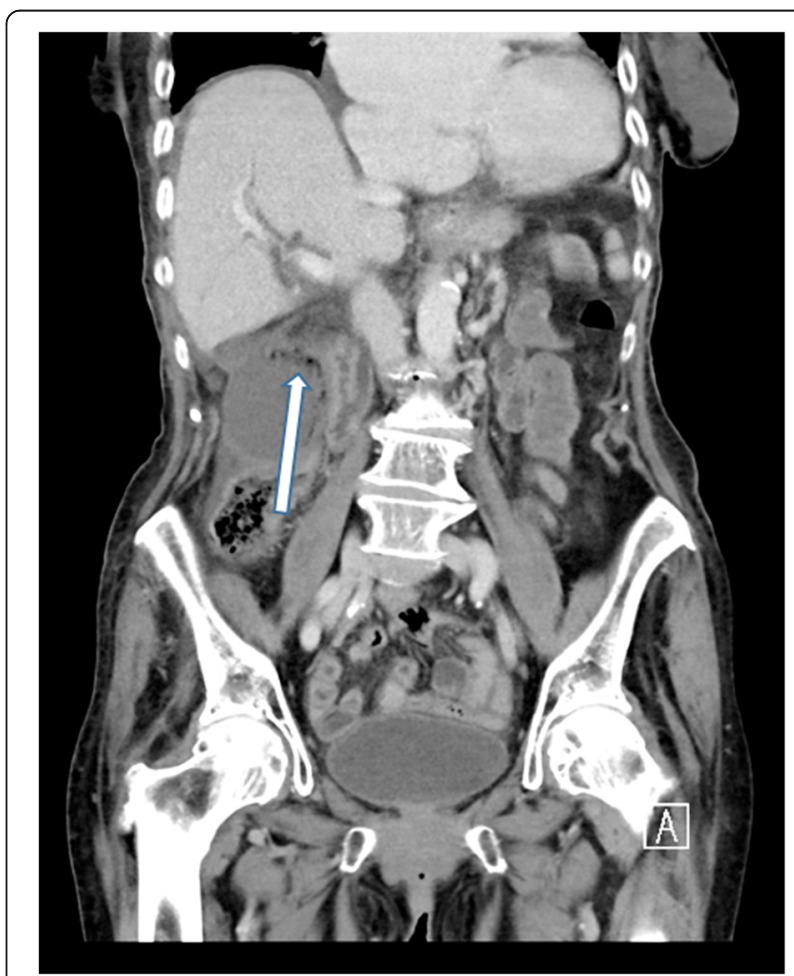

Fig. 11 Coronal contrast-enhanced CT of the abdomen demonstrating a markedly distended gallbladder. There are multiple locules of gas within the anti-dependent gallbladder wall (arrow). Findings are consistent with emphysematous cholecystitis 


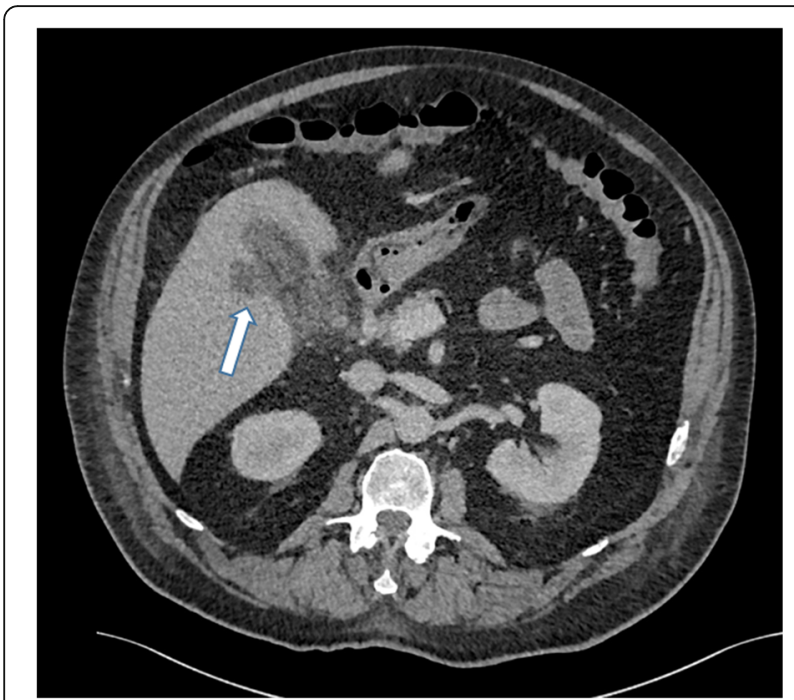

Fig. 12 Axial contrast-enhanced $C T$ of the abdomen. There is gallbladder wall thickening and pericholecystic fluid consistent with acute cholecystitis. There is a defect in the medial gallbladder wall with a hypoattenuating collection within segment 5 of the liver (arrow). Appearances are consistent with gallbladder perforation and hepatic abscess

acute cholecystitis, the gallbladder is usually shrunken down and the wall is thickened and scarred.

Emphysematous cholecystitis (EC) is a particular entity in which the gallbladder wall becomes necrotic, and this typically occurs with bacterial organisms such as the gas forming organisms such as clostridium, or with E. coli infections. Although rare, EC is associated with high mortality secondary to gallbladder perforation and gangrene, and EC is seen more commonly in patients with diabetes mellitus, coronary artery disease and SIRS (systemic inflammatory response syndrome) [8]. On plain films and $\mathrm{CT}$, gas can be seen within the gallbladder wall (Fig. 11).

If an episode of acute cholecystitis is particularly severe or left untreated, it can progress to a gallbladder perforation. This can be appreciated on US or on CT and MRI with pericholecystic abscesses or a defect in the gallbladder wall and a rim of bilious fluid outside of the gallbladder (Fig. 12). There may be an associated intrahepatic abscess which may require radiological or surgical drainage. Other rare complications of severe cholecystitis include cholecysto-cutaneous fistula and thrombophlebitis of a recanalised umbilical vein (Figs. 13 and 14).

Along the spectrum of chronic cholecystitis is the porcelain gallbladder, where calcification of the gallbladder wall is caused by repeated episodes of cholecystitis (Fig. 15). There is evidence of a causal relationship between gallstones, chronic cholecystitis and gallbladder carcinoma (Fig. 16), and malignancy often presents at an advancedstage; however, definitive proof is lacking [15].

A gallbladder mucocoele results when a stone obstructs the cystic duct causing the gallbladder to become distended with bile. When the bile within the mucocoele becomes infected, this is known as a gallbladder empyema (Fig. 17).

Mirizzi syndrome refers to a gallstone that is impacted in the cystic duct or neck of gallbladder which causes extrinsic compression on the common bile duct resulting in obstructive jaundice (Fig. 18).

Both biliary dilatation and the offending gallstone can be seen on ultrasound; however, cross-sectional

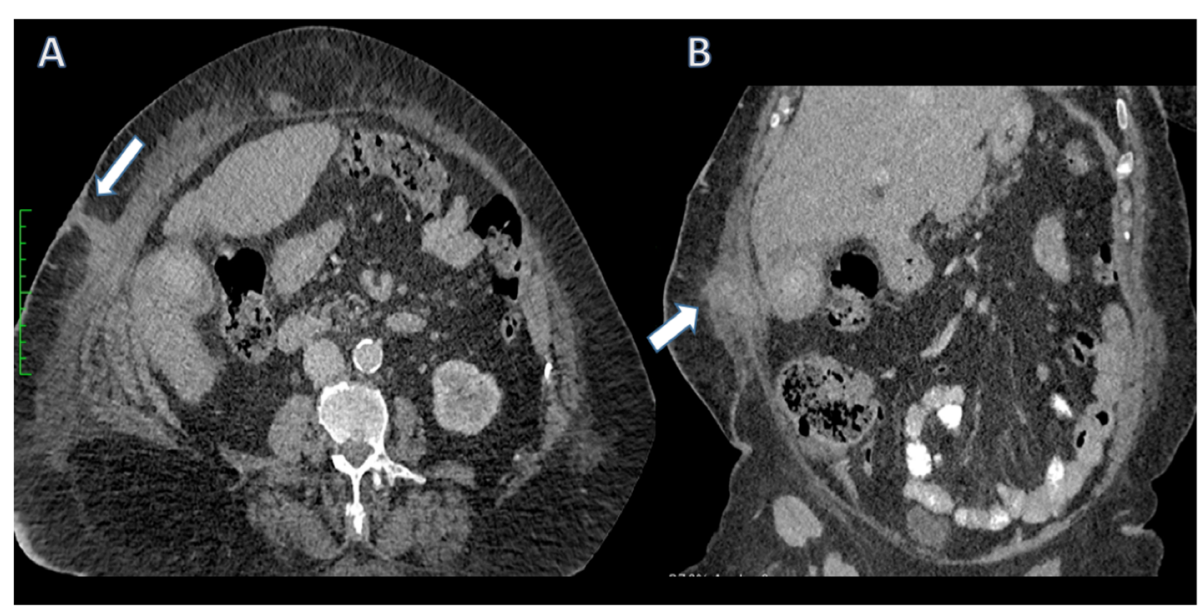

Fig. 13 Axial (a) and coronal (b) contrast-enhanced CT of the abdomen. There is extensive gallbladder wall thickening and stranding with the inflammatory process extending through the peritoneum to the right anterolateral abdominal wall with fistulation to the skin (arrows) 


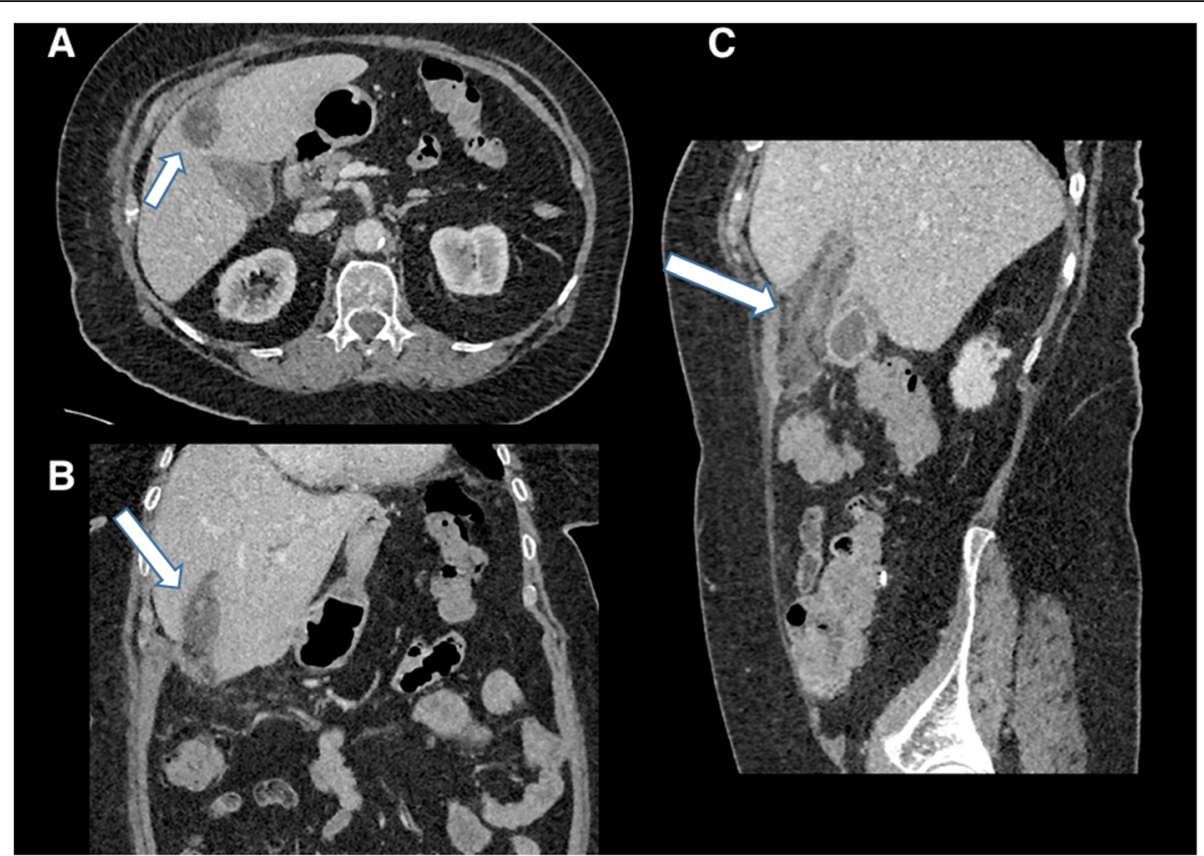

Fig. 14 Axial (a), coronal (b) and sagittal (c) contrast-enhanced CT of the abdomen. There is gallbladder wall thickening and pericholecystic fluid consistent with acute cholecystitis. There is marked expansion and oedema surrounding the falciform ligament (arrows). Appearances are due to thrombophlebitis of a recanalised umbilical vein

imaging with MRI or CT, or ERCP, may be needed to confirm that biliary dilatation is secondary to compression from a gallbladder/cystic duct stone rather than secondary to a CBD calculus.

\section{Pancreaticobiliary system}

The next anatomical location where gallstones can be found is outside the gallbladder but within the pancreaticobiliary system. When gallstones exit the gallbladder into the common bile duct (choledocholithiasis), they can often obstruct the normal drainage of bile which can lead to jaundice. This is typically associated with pain, unlike malignant biliary obstruction which is characteristically painless (Fig. 19).

The obstruction of biliary drainage and stasis of bile may result in infection in the form of ascending

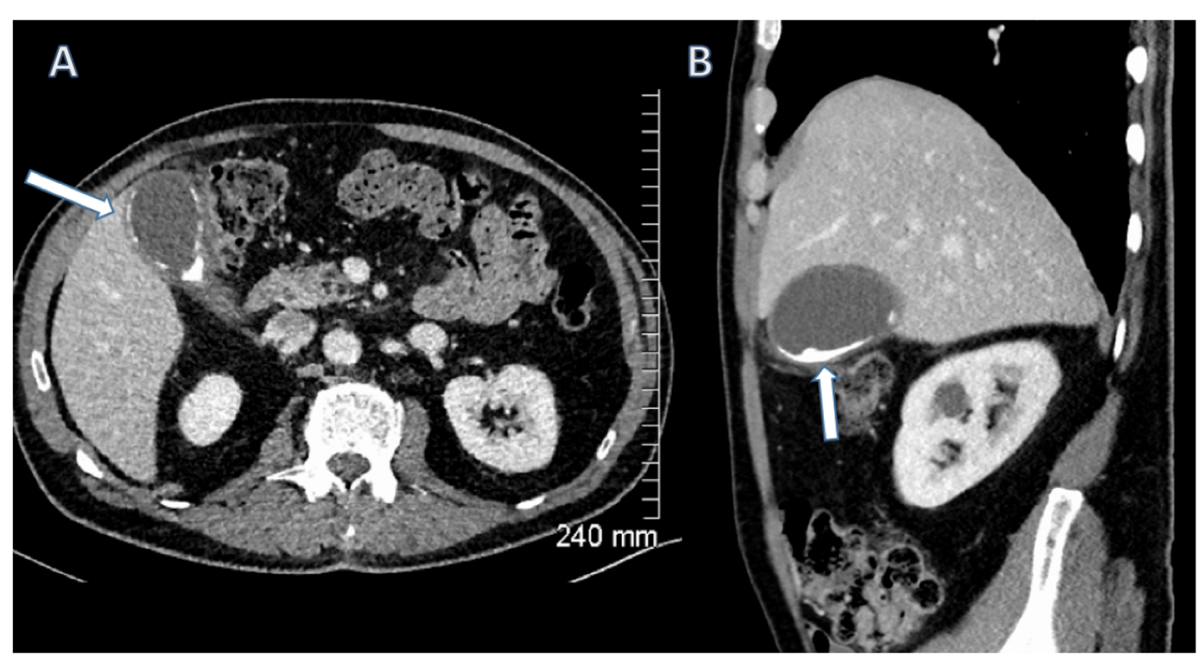

Fig. 15 Axial (a) and sagittal (b) contrast-enhanced $C T$ of the abdomen demonstrating peripheral calcification of the gallbladder wall (arrows) consistent with porcelain gallbladder 


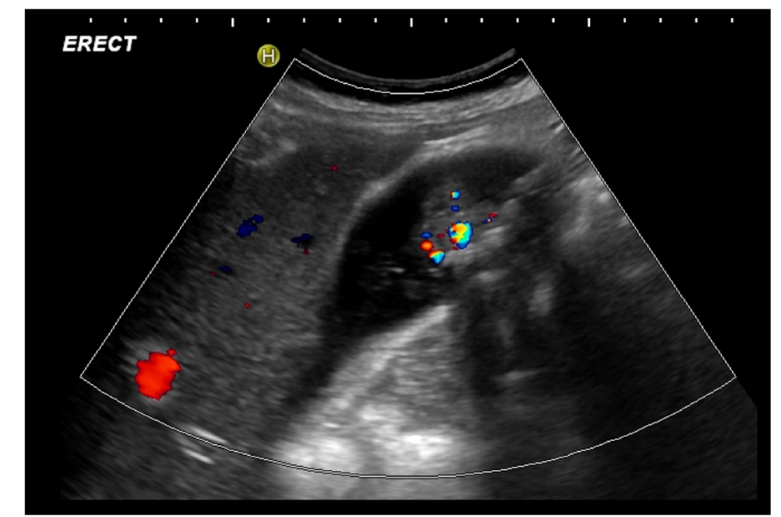

Fig. 16 Sagittal ultrasound of the gallbladder demonstrating a soft tissue mass within the gallbladder with internal vascularity consistent with a gallbladder carcinoma

cholangitis and associated sepsis. The clinical picture associated with this is described in Reynolds' pentad consisting of fever, right upper quadrant pain, jaundice, hypotension and altered mental status. These patients may require urgent decompression of the biliary system.

In rare cases, there can be retrograde passage of gallstones into the common hepatic duct or the right or left main hepatic ducts, or stones can form in intrahepatic ducts due to biliary stasis.

If a gallstone passes down the common bile duct and comes to rest at the ampulla of Vater, it may block the drainage of the pancreatic duct causing back pressure on the pancreatic cells and resulting in gallstone pancreatitis. These patients present with epigastric pain radiating to the back and the severity ranges from mild to severe. There is a significant mortality associated with severe pancreatitis, and critically ill patients should be managed in a high dependency or intensive care monitored environment. While imaging is not usually required or indicated to confirm the diagnosis of acute pancreatitis, an ultrasound of the gallbladder can confirm or rule out the presence of gallstones. CT abdomen/pelvis is best performed $48 \mathrm{~h}$ after the onset of symptoms to assess for complications of pancreatitis such as peripancreatic collections or pancreatic necrosis (Fig. 20).

In general, larger gallstones are more likely to obstruct higher in the common bile duct, and as such are more likely to cause obstructive jaundice or cholangitis. Smaller gallstones are more likely to cause pancreatitis as they more freely pass down to the level of the ampulla of Vater $[4,5]$.

\section{Extra-biliary complications}

Gallstones can also cause pathology outside of the biliary system. The most common cause, although rare, is a cholecystoenteric fistula. Chronic irritation from a large gallstone can erode through the gallbladder wall with fistulisation into small bowel. This can be seen on imaging with air seen within the gallbladder or biliary tree (pneumobilia).

When a gallstone passes through the fistula into the small bowel, this can result in intestinal obstruction, either proximal or more commonly distal. The most common place for distal small bowel obstruction and gallstone ileum is at the level of ileocecal

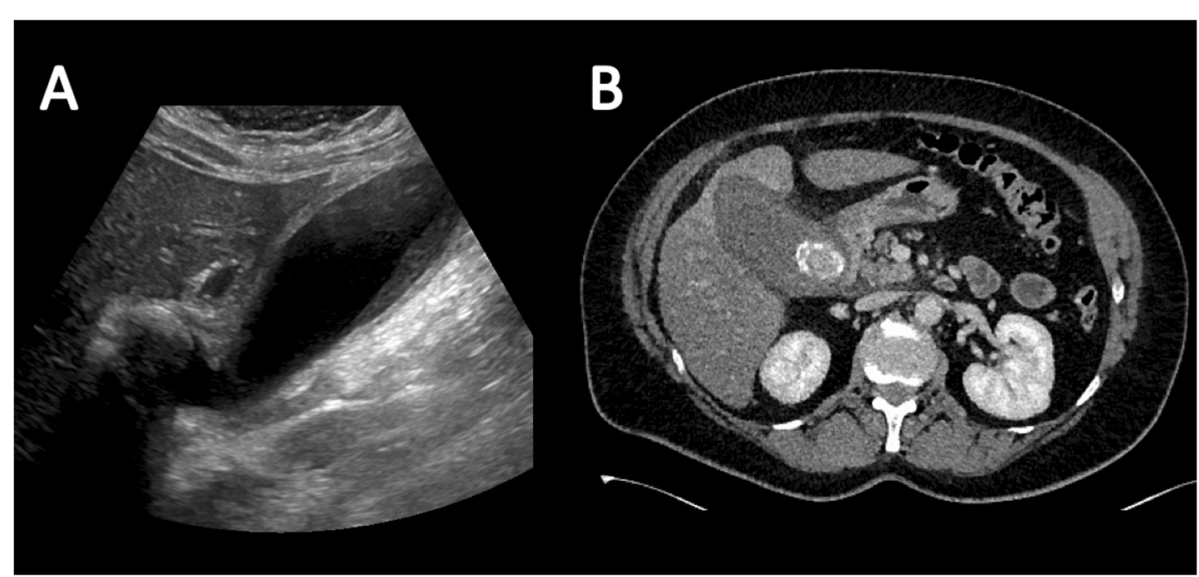

Fig. 17 a Sagittal ultrasound of a distended gallbladder with an impacted stone in the gallbladder neck. Mild associated gallbladder wall thickening. b Axial contrast-enhanced CT of the abdomen in the same patient, again demonstrating a distended gallbladder with an impacted hyperattenuating stone in the gallbladder neck. There is subtle associated fat stranding. Findings are consistent with a gallbladder mucocoele. The gallbladder wall thickening and fat stranding are suggestive of possible empyema 


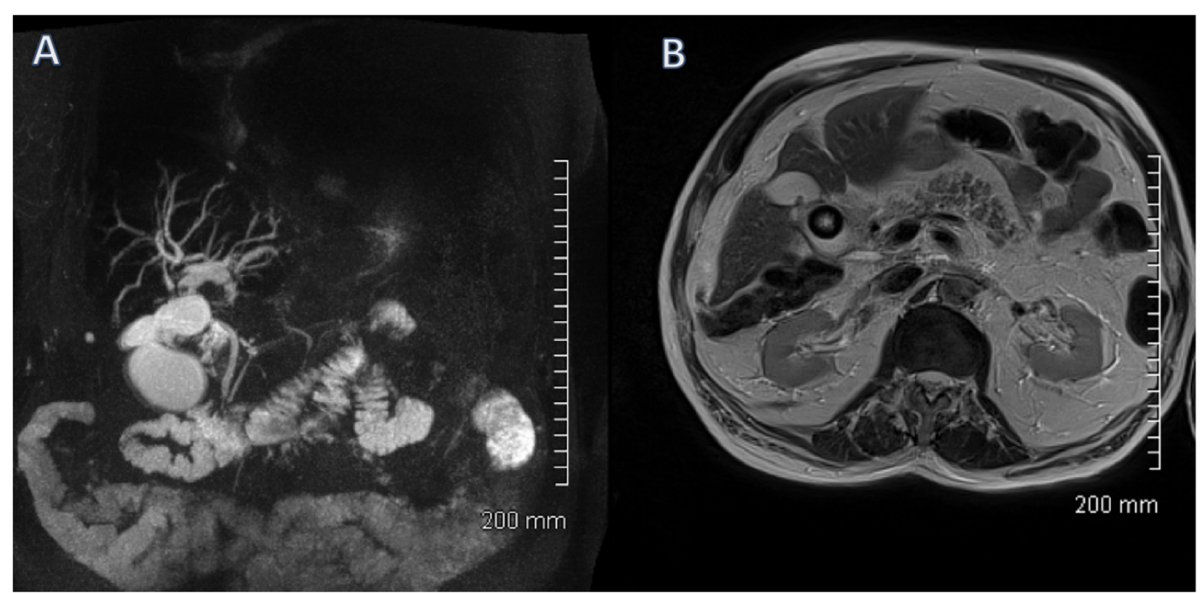

Fig. 18 a Maximum intensity projection (MIP). b Axial T2-weighted MRCP image of the biliary tree. The gallbladder is distended with extensive intrahepatic biliary duct dilatation. The common bile duct is normal in calibre. Appearances are consistent with Mirizzi syndrome, with a stone in Hartmann's pouch of the gallbladder causing extrinsic compression of the common hepatic duct

valve as this is the narrowest point; however, gallstone ileus can occur anywhere in the gastrointestinal tract. The diagnosis is suggested on abdominal $\mathrm{X}$-ray by the presence of pneumobilia in the right upper quadrant with dilated loops of bowel consistent with bowel obstruction. Gallstone ileus is more accurately diagnosed with $\mathrm{CT}$ which may show pneumobilia or may directly demonstrate the presence of a cholecystoenteric fistula and associated bowel obstruction (Fig. 21).
Bouveret's syndrome is a particular eponymous syndrome in which a stone obstructs the upper GI tract proximally at the level of duodenum or gastric outlet. Patients typically present with copious vomiting owing to the proximal level of obstruction. There may be little or no small bowel dilatation; in particular, the X-ray abdomen may be completely normal which can falsely reassure. Imaging will demonstrate evidence of gastric outlet or duodenal obstruction related to a gallstone in the upper GI tract (Fig. 22).

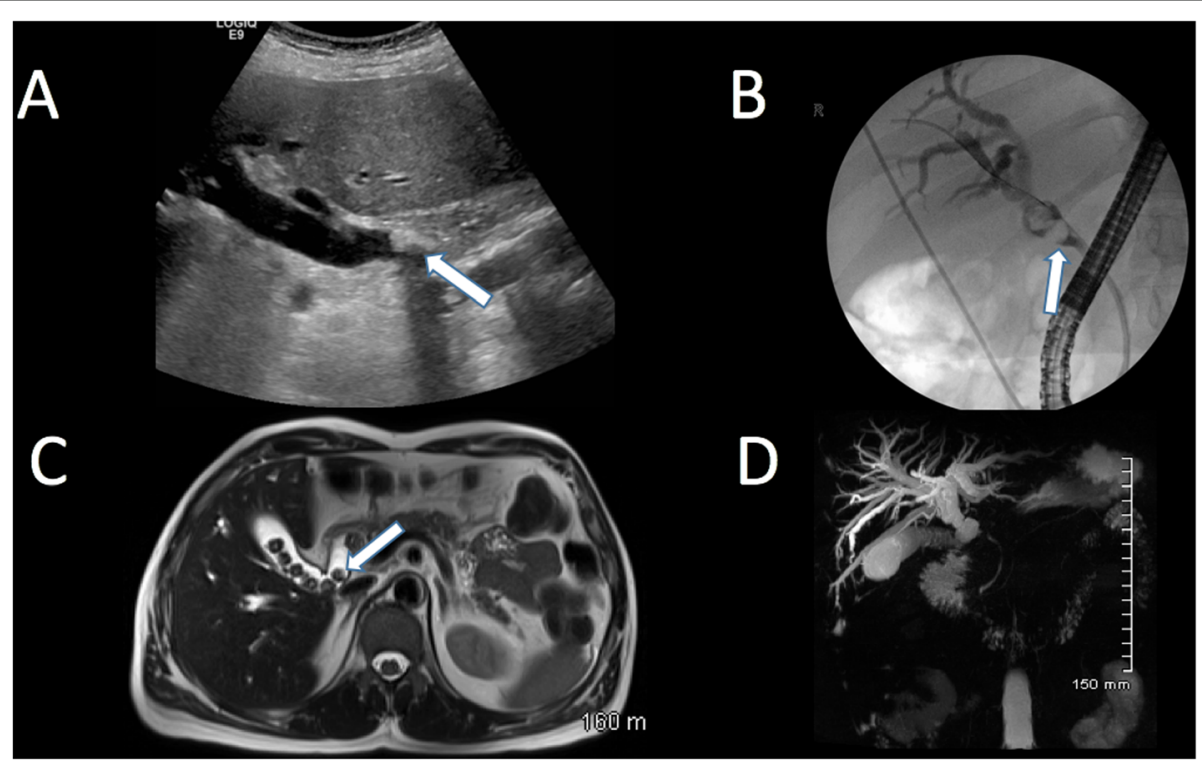

Fig. 19 (a) Sagittal ultrasound, (b) fluoroscopic ERCP cholangiogram, (c) T2-weighted axial MRI and (d) coronal MIP MRI of the biliary tree. These images demonstrate multiple filling defects (arrows) within the common bile duct with associated biliary duct dilatation consistent with obstructing choledocholithiasis 


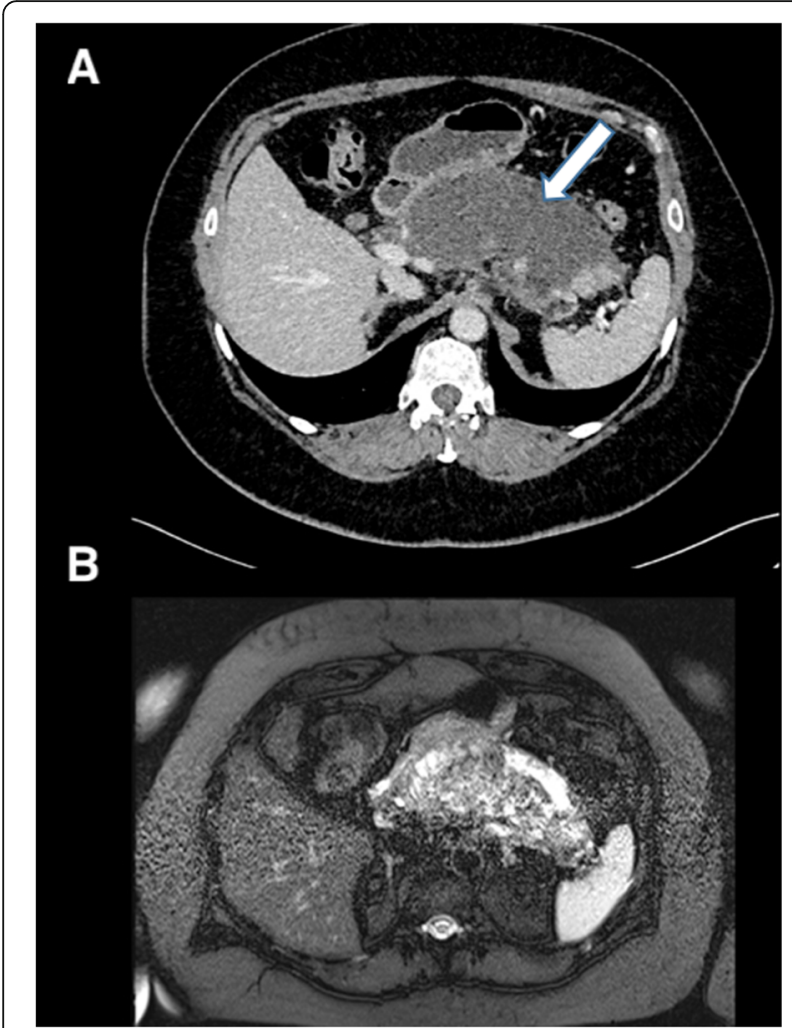

Fig. 20 Axial contrast-enhanced $C T$ of the abdomen (a) and axial fat-suppressed T2-weighted MRI of the abdomen (b) in the same patient demonstrating extensive inflammation and oedema of the pancreas secondary to gallstone pancreatitis with a peripancreatic collection (arrow)

\section{Post-surgery/cholecystectomy complications}

Finally, there are a number of imaging features post-cholecystectomy that the radiologist should be aware of. Immediate complications can include postoperative bleeding or an injury to the common bile duct resulting in a bile leak and subsequent biloma. $\mathrm{CT}$ is the optimal imaging modality for the initial imaging of post-operative complications, where these complications and fluid collections are well appreciated. It can be difficult to differentiate between blood and bile on $\mathrm{CT}$, and measuring a region of interest to obtain the Hounsfield attenuation value of the fluid can help differentiate between the two. The typical Hounsfield unit of blood is 25-75 and that of bile is usually <20; however, there can be some overlap. Other factors should be considered to ascertain the aetiology of any visualised collection, for example, a layering haemotocritl level with altered attenuation values can be a feature seen with haemorrhagic collections where the inferior denser (haemorrhagic) component is seen dependently [16] (Fig. 23).

Dropped gallstones at time of laparoscopy can have a delayed presentation with post-operative complications such as intrabdominal abscess formation and CT demonstrating a radio-opaque gallstone surrounded by abscess (Fig. 24). Gallstone abscesses without radiopaque gallstones can pose a particular diagnostic challenge as the nidus for infection is not definitely confirmed on imaging. Abscesses related to dropped gallstones can be complex and may

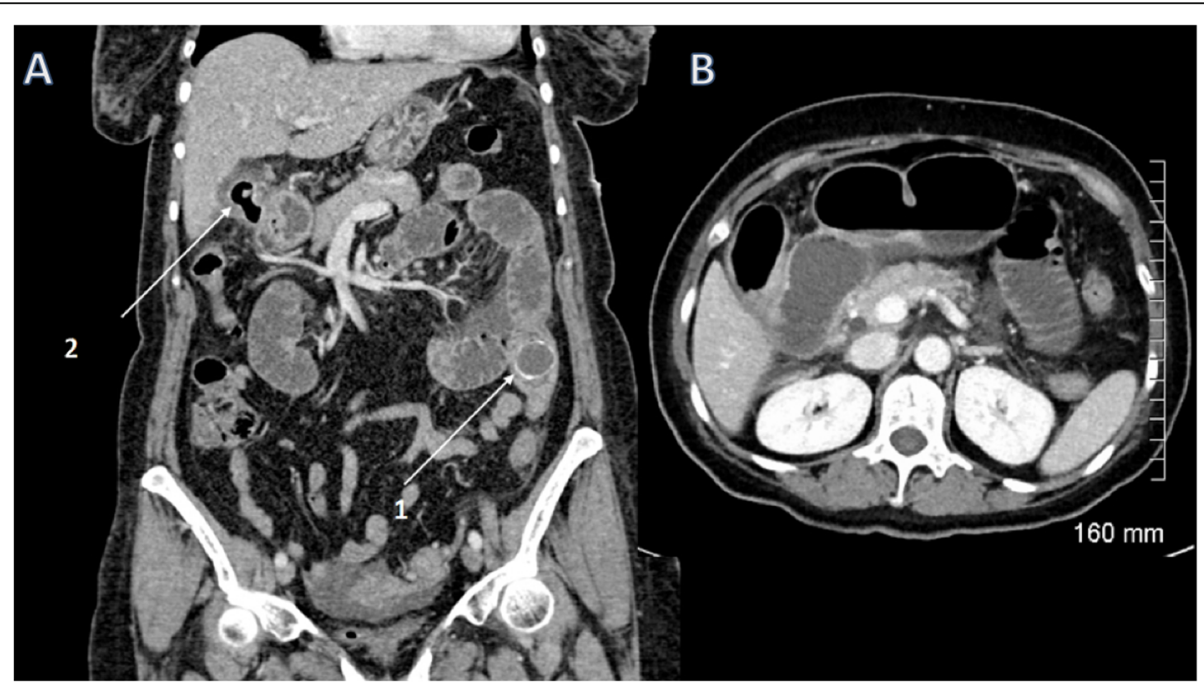

Fig. 21 Coronal (a) and axial (b) contrast-enhanced CT of the abdomen demonstrating multiple dilated loops of small bowel. There is a 3-cm peripherally hyperattenuating obstructing gallstone in the left flank (arrow 1). There is an extensive inflammatory process in the gallbladder bed with air in the gallbladder (arrow 2) consistent with a cholecystoenteric fistula. Appearances are consistent with a bowel obstruction secondary to a gallstone ileus 


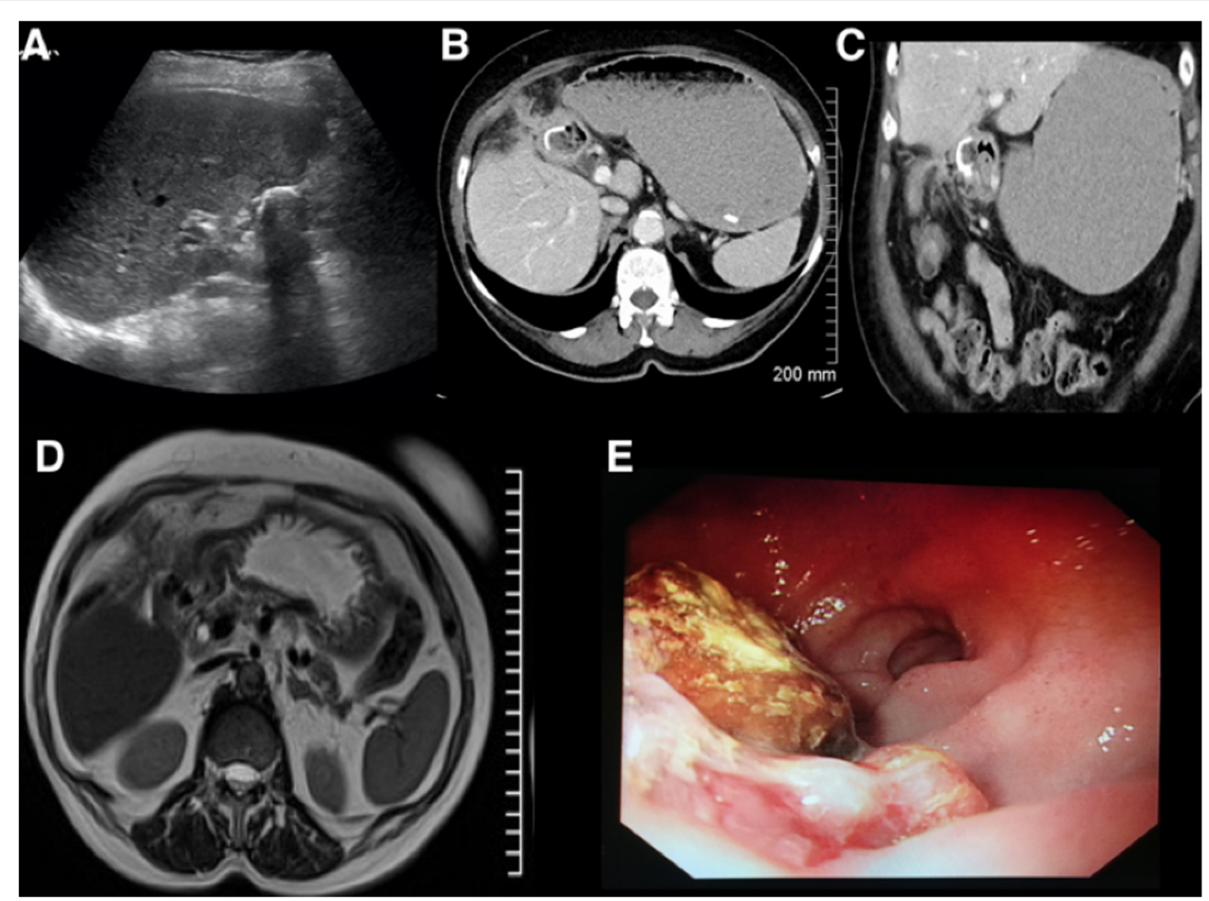

Fig. 22 Ultrasound (a), CT (b, c), MRI (d) and endoscopic images (e). Demonstrating a large calcified gallstone in the proximal duodenum with a massively dilated stomach. Findings are consistent with a proximal bowel obstruction consistent with Bouveret's syndrome

extend through abdominal planes and extend extraperitoneally into adjacent subcutaneous and soft tissue plains. The clinical history will often include a history of prior or difficult cholecystectomy. Gallbladder clips or an absent gallbladder can be seen on cross-sectional imaging as clues.

Patients with occult choledocholithiasis that proceed to cholecystectomy can present with obstructive jaundice and cholangitis in the post-operative period. It is important that any patient in whom choledocholithiasis is suspected undergo MRCP prior to surgery. Alternatively, an intra-operative cholangiogram or choledochoscope can be performed intra-operatively to ensure the common bile duct is clear of stones. Late post-cholecystectomy complications can include stump cholecystitis or a retained cystic duct stump or

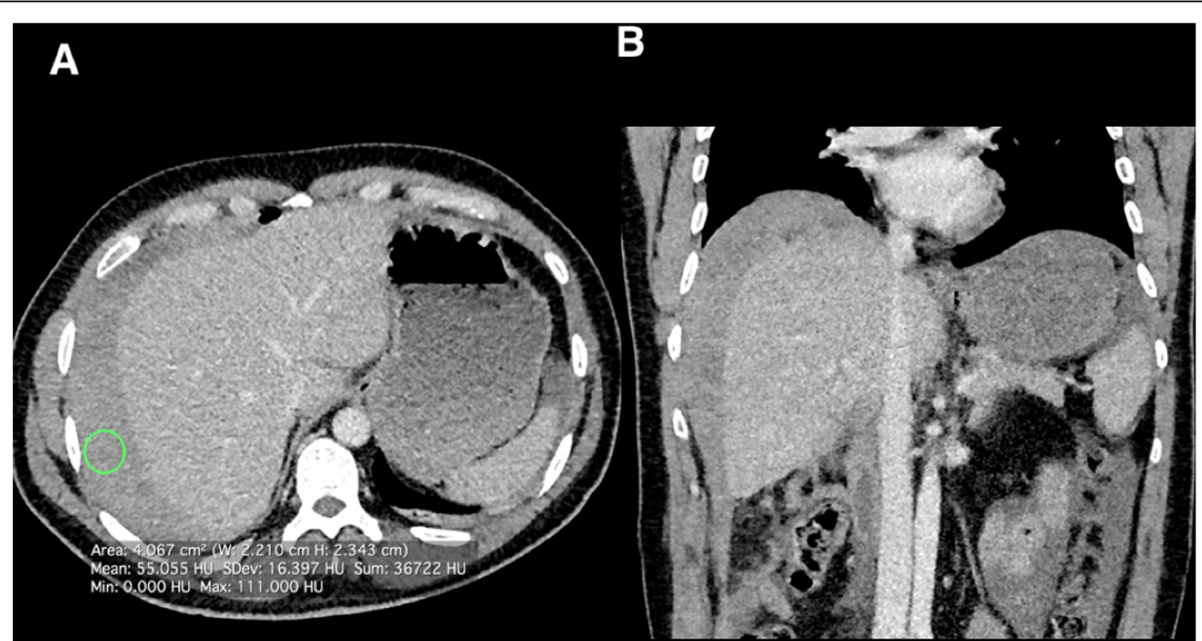

Fig. 23 Axial and coronal contrast enhanced CT of the abdomen in a patient several hours post-cholecystectomy. There is large volume perihepatic fluid with an average Hounsfield unit of 55 consistent with post-cholecystectomy bleeding 


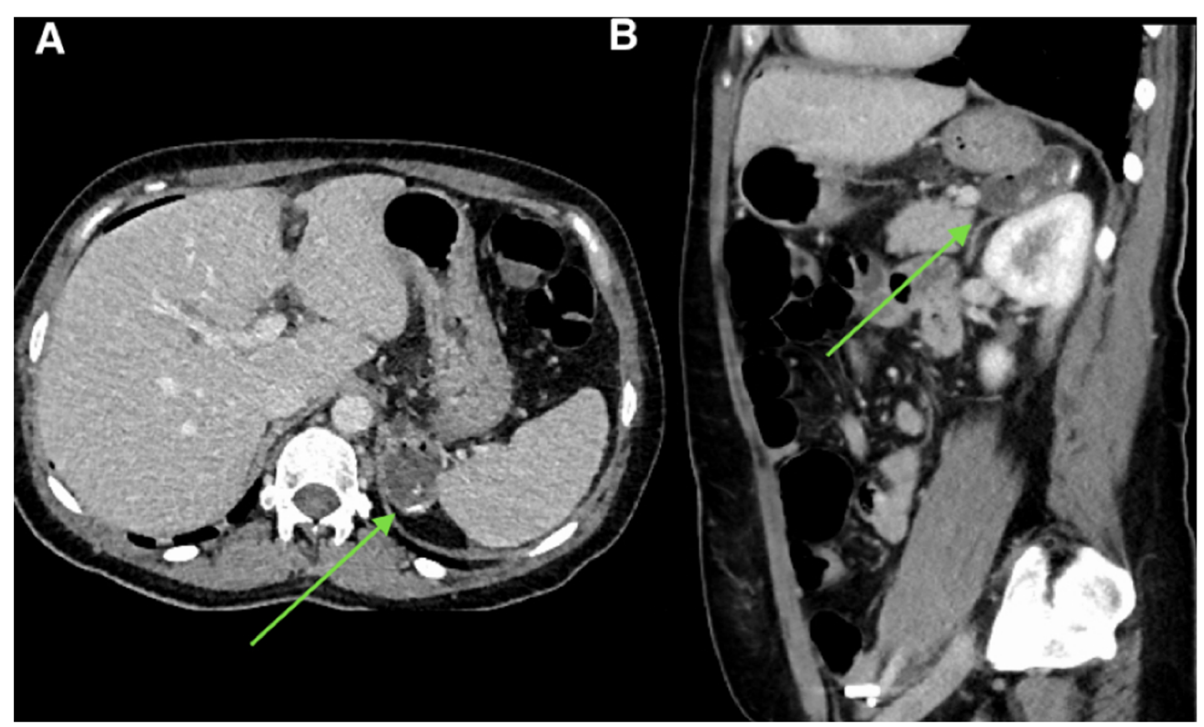

Fig. 24 Axial and sagittal images of a contrast-enhanced $C T$ abdomen in a patient several days post-laparoscopic cholecystectomy. There is a rim-enhancing fluid collection compatible with an abscess which contains multiple (dropped) gallstones

common bile duct stone. These findings result from incomplete cholecystectomy and can be identified on imaging [17] (Fig. 25).

\section{Conclusion}

Radiologists should be familiar with the wide range of pathological processes that can be seen secondary to gallstones in order to aid prompt diagnosis, treatment and intervention

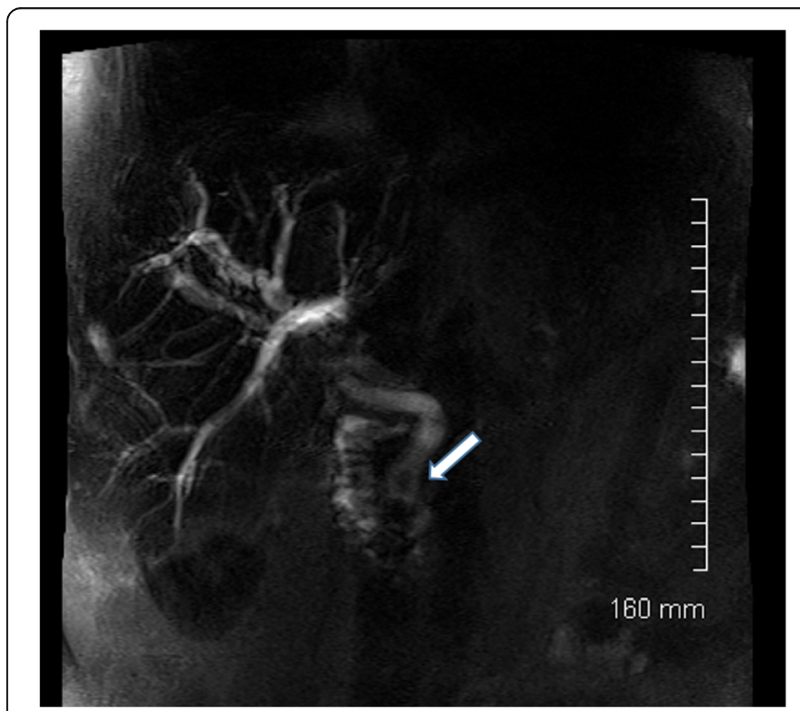

Fig. 25 Coronal magnetic resonance MIP image of the biliary tree. The gallbladder is absent consistent with a prior cholecystectomy. There is a filling defect in the distal common bile duct (arrow) with associated biliary duct dilatation consistent with an obstructing gallstone
It is hoped that through understanding the role of multimodality imaging and understanding the anatomic locations of the manifestations of gallstone-related disease, this review paper will assist the radiologist in diagnosing common and less common manifestations of gallstone-related pathology.

\section{Abbreviations}

CBD: Common bile duct; CT: Computed tomography; EC: Emphysematous cholecystitis; ERCP: Endoscopic retrograde cholangiopancreatography; IR: Interventional radiology; MRCP: Magnetic resonance cholangiopancreatography; MRI: Magnetic resonance imaging; SIRS: Systemic inflammatory response syndrome

\section{Authors' contributions}

MM contributed to the drafting of manuscript, image provision and final approval of manuscript. BG contributed to the manuscript edits and image provision. CG contributed to the manuscript edits and image provision. JH contributed to the manuscript edits and image provision. FB contributed to the manuscript edits, image provision and final approval of manuscript. All authors read and approved the final manuscript.

Funding

None.

Availability of data and materials Not applicable.

Ethics approval and consent to participate Not required.

\section{Consent for publication}

All imaging is completely anonymised with no patient identifiers.

Competing interests

The authors declare that they have no competing interests. 
Received: 17 September 2019 Accepted: 5 December 2019

Published online: 05 February 2020

\section{References}

1. Everhart JE, Khare M, Hill M, Maurer KR (1999) Prevalence and ethnic differences in gallbladder disease in the United States. Gastroenterology 117(3):632-9. https://www.ncbi.nlm.nih.gov/m/pubmed/10464139/

2. Friedman GD, Raviola CA, Fireman B (1989) Prognosis of gallstones with mild or no symptoms; 25 years of follow up in a health maintenance organisation. J Clin Epidemiol https://doi.org/10.1016/0895-4356(89)90086-3

3. Thistle JL, Cleary PA, Lachin JM, Tyor MP, Hersh T (1984) The natural history of cholelithiasis: the national cooperative gallstone study. Ann Intern Med https://doi.org/10.7326/0003-4819-101-2-171

4. Shabanzadeh DM, Sørensen LT, Jørgensen T (2016) A prediction rule for risk stratification of incidentally discovered gallstones: results from a large cohort study. Gastroenterology. https://doi.org/10.1053/j.gastro.2015.09.002

5. Friedman G (1993) Natural history of asymptomatic and symptomatic gallstones. Am J Surg 165:399-404

6. Bortoff GA, Chen MY, Ott DJ, Wolfman NT, Routh WD (2000) Gallbladder stones: imaging and intervention. Radiographics 20(3):751-66

7. Clavien PA, Baillie J (Eds) (2006) Diseases of the Gallbladder and Bile Ducts: Diagnosis and Treatment, Second Edition. Wiley-Blackwell Press. https://doi. org/10.1002/9780470986981

8. O'Connor OJ, Maher MM (2011) Imaging of cholecystitis. AJR Am J Roentgenol 196:W367-W374 https://doi.org/10.2214/AJR.10.4340

9. Meyers MA, O'Donohue N (1973) The Mercedes-Benz sign: insight into the dynamics of formation and disappearance of gallstones. Am J Roentgenol Radium Ther Nucl Med https://doi.org/10.2214/ajr.119.1.63

10. Chen AL, Liu AL, Wang $S$ et al (2015) Detection of gallbladder stones by dual-energy spectral computed tomography imaging. World I Gastroenterol https://doi.org/10.3748/wjg.v21.i34.9993

11. O'Connor OJ, O'Neill S, Maher MM (2011) Imaging of biliary tract disease. AJR Am J Roentgenol https://doi.org/10.2214/AJR.10.4341

12. Chen W, Mo JJ, Lin L, Li CQ, Zhang JF (2015) Diagnostic value of magnetic resonance cholangiopancreatography in choledocholithiasis. World J Gastroenterol 21(11):3351-3360 https://doi.org/10.3748/wjg.v21.i11.3351

13. Maher M, Dixon AK (2015) Grainger \& Allison's diagnostic radiology: abdominal imaging. Elsevier, ISBN: 9780702069383 ISBN: 9780702069383

14. Shea JA, Berlin JA, Escarce JJ et al (1994) Revised estimates of diagnostic test sensitivity and specificity in suspected biliary tract disease. Arch Intern Med 154(22):2573-81

15. Shrikhande SV, Barreto SG, Singh S, Udwadia TE, Agarwal AK (2010) Cholelithiasis in gallbladder cancer: coincidence, co-factor or cause? Eur J Surg Oncol https://doi.org/10.1016/j.ejso.2010.05.002

16. Vazquez $\mathrm{LL}$, Thorsen MK, Dodds WJ et al (1985) Evaluation and treatment of intraabdominal bilomas. AJR Am J Roentgenol. https://doi.org/10.2214/ ajr.144.5.933

17. Chowbey P, Sharma A, Goswami A et al (2015) Residual gallbladder stones after cholecystectomy: a literature review. J Minim Access Surg https://doi. org/10.4103/0972-9941.158156

\section{Publisher's Note}

Springer Nature remains neutral with regard to jurisdictional claims in published maps and institutional affiliations.

\section{Submit your manuscript to a SpringerOpen ${ }^{\circ}$ journal and benefit from:}

- Convenient online submission

- Rigorous peer review

- Open access: articles freely available online

- High visibility within the field

- Retaining the copyright to your article

Submit your next manuscript at $\boldsymbol{\nabla}$ springeropen.com 